\title{
Focal Segmental Glomerulosclerosis Cellular Variant
}

National Cancer Institute

\section{Source}

National Cancer Institute. Focal Segmental Glomerulosclerosis Cellular Variant. NCI

Thesaurus. Code C123051.

A variant of FSGS characterized by hypercellularity of the glomerulus; this excludes the tip and collapsing FSGS. (D'Agati VD, et al. "Pathologic Classification of Focal Segmental Glomerulosclerosis: A Working Proposal." Am J Kidney Dis 43.2 (2004): 368-82.) 